\title{
O ACESSO ÀS TECNOLOGIAS DE INFORMAÇÃO E DE COMUNICAÇÃO E A SUPERAÇÃO DAS LIMITAÇÕES DOS PNEES COM LIMITAÇAO VISUAL INCLUINDO-OS EM UM AMBIENTE DE APRENDIZAGEM MEDIADO POR COMPUTADOR
}

\author{
Lizandra Brasil Estabel ${ }^{1}$ \\ Eliane Lourdes da Silva Moro ${ }^{2}$ \\ Lucila Maria Costi Santarosa ${ }^{3}$
}

\begin{abstract}
RESUMO: Este trabalho apresenta a verificação da acessibilidade ao ambiente TelEduc através do uso das ferramentas e da interação entre os participantes e entre estes e os formadores. Os sujeitos são Pessoas com Necessidades Especiais (PNEs) com limitação visual que atuam como professores em escolas públicas e instituições não-governamentais contempladas com laboratórios de informática, de várias regiões do país, participantes do Programa Nacional de Informática na Educação Especial (PROINESP), da Secretaria de Educação Especial, do Ministério da Educação (SEEsp/MEC) ministrado pela equipe do Núcleo de Informática na Educação Especial (NIEE), da Universidade Federal do Rio Grande do Sul (UFRGS), coordenado pela Prof. Dr ${ }^{\mathrm{a}}$ Lucila Maria Costi Santarosa. Verifica o uso e o acesso das Tecnologias de Informação e de Comunicação (TICs) possibilitando a interação entre os participantes e a inclusão social e digital.
\end{abstract}

PALAVRAS-CHAVE: Pessoas com Necessidades Especiais com limitação visual; Tecnologias de Informação e de Comunicação, Acessibilidade.

ABSTRACT: This work presents the verification of the accessibility to the TelEduc environment through the use of the tools and the interaction between the participants and these and the tutors. The People with Special Needs with visual limitation that act teachers in public schools and no-government institutions meditated with computer science laboratories, of several areas of the country, participants of the PROINESP, of the General office of Special Education, of Ministry of Education (SEEsp/MEC) supplied by the team of the NIEE, of the UFRGS, coordinated by Prof. Dr ${ }^{\mathrm{a}}$ Lucila Maria Costi Santarosa. Verifies the use and the access of the Technologies of Information and of Communication (TICs) making possible the interaction between the participants and the social and digital inclusion.

KEYWORDS: People with Special Needs with visual limitation; Information and Communication Technologies; accessibility.

\section{INTRODUÇÃO}

"A minha cegueira é uma forma de visão"! Dentro da sua cegueira,
compreendeu que sempre vira com o corpo inteiro. Via com os pés,
que lhe indicavam as mudanças de solo; via com as mãos, com a
face; via por todos os poros do seu corpo e continuava vendo, todo
um espetáculo interior que habitava o seu íntimo, a sua mente, e
dialogava com o mundo exterior de um modo próprio, o seu modo de

1 Professora do Curso de Biblioteconomia da FABICO/UFRGS, Especialista em Informática na Educação PGIE/UFRGS, Doutoranda em Informática na Educação - PGIE/UFRGS, Bibliotecária do Colégio Mãe de Deus e do Instituto Santa Luzia. E-mail:estabel@cpovo.net .

2 Professora do Curso de Biblioteconomia da FABICO/UFRGS, Especialista em Informática na Educação PGIE/UFRGS, Mestranda do Programa de Pós-Graduação em Educação da UFRGS - PPGEdu/UFRGS, Coordenadora do Núcleo da Hora do Conto do DCI/FABICO/UFRGS. E-mail: eliane_moro@yahoo.com.br.

${ }_{3}^{3}$ Professora Doutora do PPGEDU e do PGIE/UFRGS, Coordenadora Nacional da RIBIE, Coordenadora de Pesquisa do NIEE-UFRGS. E-mail: lucila.santarosa@ufrgs.br

V. $3 \mathrm{~N}^{\circ} 1$, Maio, 2005 
"ver". Percebeu como a experiência da cegueira acha-se ela própria "imunda" de visão, e as tantas vezes em que tivera vergonha disso, as tantas vezes em que negaceara essa visão olfativa, auditiva, todos os "órgãos de ver", espalhados por seu corpo a fora, e que lhe tinham sido revelados pela lição das pedras! (JOANA BELARMINO)

Segundo dados da Organização Mundial de Saúde (OMS) existem aproximadamente 40 milhões de pessoas com necessidades especiais (PNEs) com limitação visual no mundo, das quais $75 \%$ são provenientes de regiões de baixo poder sócio-econômico. No Brasil, a incidência de PNEs com limitação visual está na faixa de 1,0 a $1,5 \%$ da população, sendo de uma entre 3.000 crianças com cegueira, e de uma entre 500 crianças com baixa visão. A proporção é de $80 \%$ de pessoas com baixa visão e de $20 \%$ de pessoas totalmente cegas.

Conforme ARANHA (2003, p. 188) calcula-se que os dados estimados poderiam ser reduzidos pelo menos à metade, se fossem tomadas medidas preventivas eficientes. O censo escolar/2002, dados do Instituto Nacional de Estudos e Pesquisas Educacionais Anísio Teixeira (INEP/MEC) registra 20.257 alunos com deficiência visual na educação básica do sistema educacional brasileiro. A análise desses dados reflete que muitas crianças, jovens e adultos com limitação visual encontram-se fora da escola.

Dados do Censo 2000 do Instituto Brasileiro de Geografia e Estatística (IBGE), apontam que $14,5 \%$ da população brasileira é formada por PNEs e destes, $48 \%$ são consideradas PNEs com limitação visual. Considera-se, de acordo com os dados apresentados, que metade da população de PNEs possui limitação visual, tornando necessário e urgente a implantação de políticas governamentais de inclusão social, digital e educacional com acesso às Tecnologias de Informação e de Comunicação (TICs).

Pode-se considerar que existe uma parcela considerável de pessoas com limitação visual em nossa sociedade, residentes em regiões de baixo poder sócio-econômico e excluídos da escola. Não são poucas as dificuldades enfrentadas pelas PNEs com limitação visual, além das limitações impostas pela cegueira, encontra-se em nossa sociedade dificuldades em relação ao acesso às TICs, acesso este que poderia auxiliá-los na sua formação educacional, profissional e na sua inclusão social e digital como cidadãos.

\begin{abstract}
Está na hora de discutir o direito de entrar numa biblioteca ou livraria e ter acesso a um livro em Braille ou digitalizado. Está na hora de discutir o direito de ter acesso à informação em Braille ou digitalizada em restaurantes, farmácias, supermercados e demais locais públicos e privados. Está na hora de discutir a inclusão do cego pelo seu mérito pessoal, abandonando de vez o caráter demagógico e assistencialista que ainda prevalece em muitos setores. Está na hora de conhecer a história de brasileiros que lutam diariamente pela sua inclusão numa sociedade que os ignora e não os enxerga como homens e mulheres com valores, conhecimentos, anseios e sonhos iguais aos de todo mundo.(DIAS, 2005)
\end{abstract}

Este olhar diferenciado para as PNEs com limitação visual somente será modificado quando a sociedade discutir este tema, estiver aberta para ouvi-los, buscar formas de adaptação e acessibilidade, como as tecnologias assistivas e

\footnotetext{
${ }^{4}$ Documento eletrônico
} 
buscar a inclusão das pessoas com as suas limitações, em uma sociedade de tantas diversidades. Segundo Belarmino (2005) "a visão é uma forma de cegueira", mas antes, "a visão que os homens têm a respeito da cegueira é também uma forma de visão", que tanto pode servir para "juntar" as diferenças como para apartá-las".

O acesso à escola muitas vezes é dificultado pela falta de informação e/ou qualificação dos profissionais da educação no ensino de Pessoas com Necessidades Educacionais Especiais (PNEEs) com limitação visual. As escolas não possuem materiais adaptados para este público, com raras exceções, como obras em Braille, sistema de escrita das PNEs com limitação visual, ou equipamentos tecnológicos adaptados para atendê-los em suas necessidades. A dificuldade de acesso às TICs é um outro problema enfrentado pelos cegos, pois as bibliotecas não disponibilizam materiais especiais como livros em Braille, fitas sonoras, entre outros. Verifica-se uma grande dificuldade de produção e distribuição desses livros especiais, pois é necessário digitá-los ou digitalizá-los para depois imprimi-los em uma impressora Braille. A aquisição da impressora tem um custo bastante elevado e, por outro lado, existe um desconhecimento em relação aos softwares e equipamentos adaptados às PNEEs com limitação visual.

Acredita-se que, para modificar esta situação, é preciso investir na educação e em recursos para os ambientes de aprendizagem que são suporte na extensão da sala de aula como laboratórios e bibliotecas. Faz-se necessária a capacitação de professores dando-Ihes condições de compreender melhor o seu aluno, suas limitações, dificuldades e superações. Há necessidade de uma mudança nas formas de aprender e ensinar, buscando alternativas para a inclusão das PNEEs em salas de aulas, tanto na modalidade presencial, como não presencial, através da Educação a Distância mediada por computador.

\section{AS PESSOAS COM NECESSIDADES ESPECIAIS COM LIMITAÇÃO VISUAL E A EPISTEMOLOGIA VYGOTSKYANA}

Vygotski apresenta-nos a questão da cegueira e mais especificamente a criança cega, afirmando o seguinte:

- $\quad$ No contato com o meio exterior surge um conflito, causado pela falta de correspondência do órgão com a função deficiente de suas tarefas que conduz a uma alta possibilidade de enfermidade e morte. Este conflito cria também elevadas possibilidades e estímulos para a super compensação. O defeito [limitação] se converte, de tal modo, em ponto de partida e força motriz do desenvolvimento psíquico da personalidade. Se a luta termina com a vitória do organismo, este não vence somente as dificuldades criadas pelo defeito, sendo que também se eleva, em seu desenvolvimento, a um nível superior, transformando a deficiência em talento, o defeito em capacidade, a debilidade em força, a insuficiência em superação. (VYGOTSKI, 1997, p. 103).

No entanto, esta superação vai depender de como a pessoa irá se relacionar com o meio em que vive, de que forma ela estará inserida socialmente, sua relação com os outros. Muitas vezes, as PNEs com limitação

${ }^{5}$ Documento eletrônico.

V. $3 \mathrm{~N}^{\circ} 1$, Maio, 2005 
visual são consideradas como incapacitados e as pessoas demonstram sentimento de compaixão. Também ocorre o contrário, quando há uma supervalorização dos seus sentidos, afirmando que a pessoa cega tem um sexto sentido, ou um "ouvido mais apurado". Vygotski (1997, p.107) coloca que "a fonte de compensação na cegueira não é o desenvolvimento do tato ou a maior sutileza do ouvido, mas a linguagem, quer dizer, a utilização da experiência social, da comunicação com os videntes". E afirma que "a palavra vence a cegueira".

O processo de comunicação entre videntes e cegos, muitas vezes não se estabelece, em relação à escrita, quando não há o domínio do sistema Braille. Para um vidente, que nunca entrou em contato com este sistema, tornase impossível fazer a leitura do texto. Para a pessoa com limitação visual, ao ter acesso a uma folha impressa a tinta é o mesmo do que uma folha em branco. Esta constatação serve para enfatizar a importância da linguagem como instrumento de mediação no processo de comunicação entre PNEs com limitação visual e videntes. Somente na década de 90 , com o surgimento dos leitores de tela ou softwares de voz, esta situação foi modificada, na medida em que o texto escrito é lido no momento em que o cego acessa o computador. A informática é um meio facilitador ao acesso das Tecnologias de Informação e de Comunicação (TICs). As PNEs com limitação visual sentir-se-ão incluídas digitalmente, minimizando as diferenças e propiciando a interação com o outro.

Segundo Ferreyra (1998, p.30-39) os cinco sentidos a audição, o tato, o olfato, o gosto e a visão conectam o ser humano com o mundo. O autor afirma que a cultura dos meios eletrônicos proporcionou uma extensão que intensificou os sentidos do homem para promover uma nova oralidade, a ponto que "alguns cientistas da comunicação humana consideram que os meios eletrônicos estendam os nossos sentidos". A ausência de um dos sentido, no caso, a visão, pode ser superada na medida que uma tecnologia adaptativa/assistiva, possibilite a inserção da PNE com limitação visual ao ambiente digital.

Segundo Santarosa (2002, p.65 ) " [. . . ] as TICs são uma nova janela que se abre para amenizar a discriminação social existente em nossa sociedade com relação às pessoas portadoras de algum tipo de deficiência, vistas como incapazes de lidar e manusear com instrumentos mais sofisticados como são os computadores". Para Vygotski (1997, p.111) "as novas teorias não valorizam a cegueira em si nem o defeito (deficiência), mas a força contida nela, as fontes de sua superação nos estímulos para o desenvolvimento do ser".

Desta forma pode-se reforçar a importância da inclusão social e digital das PNEs em nossa sociedade, nas escolas, universidades, bibliotecas, empresas, entre outros, onde a maioria das pessoas estão inseridas. Faz-se necessário a adaptação destes ambientes, mas não a criação de ambientes isolados como escolas especiais, bibliotecas Braille, entre outros, e sim buscar formas de inserir estas pessoas em ambientes adaptados às suas necessidades. Muitas vezes, um computador com kit multimídia e a instalação de um sistema operacional, como o dosvox que é gratuito, pode solucionar o problema de acesso à informação.

É preciso eliminar a educação dos cegos baseada no isolamento e na invalidez, acabar com o limite entre a escola especial e a comum. A educação da criança cega deve ser organizada como a educação 
da criança capaz de um desenvolvimento normal; a educação deve converter realmente o cego em uma pessoa normal, socialmente incluída e desaparecer a palavra e o conceito de "deficiente" no que concerne ao cego. (VYGOTSKI, 1997, p. 112)

De acordo com Dias $(2005)^{6}$ "deficiente é a sociedade incapaz de possibilitar os meios necessários para que todos os cidadãos tenham acesso à informação".

\section{AMBIENTE DE APRENDIZAGEM MEDIADO POR COMPUTADOR E A PESSOA COM LIMITAÇÃO VISUAL}

A utilização de Ambientes de Aprendizagem Mediados por Computador (AAMCs) são a porta de entrada para a inclusão das pessoas no ambiente digital. Para a realização de cursos a distância, faz-se necessária a escolha criteriosa de um ambiente que possibilite a interação dos alunos, de forma que estes sejam agentes do seu processo de aprendizado, ficando o professor no papel de mediador, propiciando o exercício da cooperação e da colaboração na realização das atividades.

O TelEduc, ambiente de aprendizagem mediado por computador, é um ambiente de fácil utilização e apresenta ferramentas de comunicação como: correio eletrônico, diário de bordo, fórum de discussão, mural, bate-papo, entre outras. Estas ferramentas possibilitam que o aluno tenha autonomia para a realização das atividades propostas e possa estabelecer uma relação de comunicação com os demais componentes do grupo, sem necessitar da intervenção do formador.

Este ambiente está sendo utilizado no Programa Nacional de Informática na Educação Especial (PROINESP), da Secretaria de Educação Especial, do Ministério da Educação (SEEsp/MEC) ministrado pela equipe do Núcleo de Informática na Educação Especial (NIEE), da Universidade Federal do Rio Grande do Sul (UFRGS), coordenado pela Prof. Dra Lucila Maria Costi Santarosa. O curso teve início no dia 7 de março de 2005 com a carga horária de 120h. Participam do PROINESP aproximadamente 310 professores, de 155 escolas públicas e instituições não-governamentais contempladas com laboratórios de informática. O objetivo é capacitar os professores dessas instituições a trabalharem com a informática de forma a incluir os alunos com necessidades educacionais especiais no ambiente digital, propiciando a inclusão e o exercício da cidadania.

Estes professores foram divididos em quinze turmas, de aproximadamente 22 participantes em cada uma, provenientes de instituições localizadas nas diversas regiões do país. Em uma das turmas, dentre os participantes, existem 4 professores com necessidades especiais com limitação visual.

Este trabalho apresenta a verificação da acessibilidade ao ambiente através do uso das ferramentas e da interação entre os participantes e entre estes e os formadores. Para preservar a identidade dos sujeitos observados, será utilizada a denominação Prof 1, Prof 2, Prof 3 e Prof 4.

6 Documento eletrônico. 
O curso se realiza totalmente a distância, o uso da ferramenta "perfil" possibilita que os participantes conheçam uns aos outros, pois cada um deve fazer uma breve descrição sobre a sua vida, o que gosta de fazer, onde atua, entre outros. Observando os perfis, apenas um colocou que era portador de limitação visual.

Sou casado há 5 anos, tenho uma filha, que vai completar no final deste mês 4 anos, e tenho 42 anos de idade. Sou aposentado por invalidez, cego há 11 anos, por acidente de trabalho, sendo que há 5 anos, mais ou menos, ensino informática para pessoas com limitações visuais. (Prof 1).

De acordo com estudos realizados e a partir do contato diário com pessoas com limitação visual, quando há a perda da visão, diferentemente de quem nasce sem enxergar, passa a ser muito mais difícil aceitar esta condição. Esta afirmação não é uma generalização, no entanto, tem-se observado vários casos.

Para Cerejo $(2005)^{7}$

A cegueira pode ser de nascença ou verificada ao longo da vida. É comum imaginar-se que toda pessoa portadora de cegueira nasceu assim, porém muitos são os casos de pessoas que adquiriram a cegueira após determinado período de vida. Daí, a diferença que se observa no tocante às habilidades dos portadores de cegueira. Uma pessoa tendo perdido a visão há pouco tempo, dificilmente terá a mesma desenvoltura daquela que já nasceu assim, pois esta, desde o início de sua vida, não experimentou qualquer mudança; ao contrário, habituada aos recursos de que sempre dispôs, cria naturalmente seus próprios meios para vencer as diversas tarefas que se lhe apresentam.

Os demais sujeitos observados são cegos de nascença e não registraram esta condição nos seus perfis. Isso possibilita uma reflexão sobre as formas que a sociedade trata as pessoas com alguma limitação. Não são poucas as vezes que as PNEEs com limitação visual são tratadas por "ceguinhos", "aquele cego" e outras denominações. A pessoa cega deve ser respeitada como qualquer cidadão sendo tratadas pelo seu nome e não por apelidos pejorativos.

Pode-se observar no perfil desta participante do curso que, em nenhum momento, comenta sobre a sua limitação visual.

Sou pedagoga, especialista em supervisão escolar e orientação educacional, mestre em educação e educadora por excelência. Sou teimosa, adoro desafios, coisas aparentemente impossíveis! [...] Trabalho com produção braille, informática e também faço palestras e dou aulas em uma universidade particular. Sou alegre, comunicativa, adoro fazer amizades e sou cantora da noite pra poder ser professora e receber esse salário enorme! Gosto de assistir filmes interessantes, sentar num barzinho com música ao vivo e fazer caminhadas quando dá! Adoro essa magia que é cada novo dia, cada novo amigo, cada nova aventura! (Prof 2)

\footnotetext{
${ }^{7}$ Documento eletrônico.
} 
Este perfil possibilita que o grupo interaja com a colega sem tratá-la de forma diferente, desconhecendo a sua limitação e possibilitando que ela também não sinta nenhuma discriminação no contato com os demais colegas e no processo de cooperação e colaboração.

Uma das vantagens da educação a distância e das tecnologias assistivas é possibilitar o acesso às TICs de forma que as suas limitações passem desapercebidas. Se a tecnologia é a extensão da mão do homem, esta existe para minimizar as suas dificuldades ou superá-las, permitindo que os sujeitos tenham autonomia no processo de construção do seu próprio aprendizado e do grupo em que está inserido.

No entanto, apesar das diversas opções de ambientes de aprendizagem mediados por computador, enfrenta-se um sério problema em relação à acessibilidade. Estes problemas são uma barreira e uma forma de exclusão das pessoas com limitação visual, impossibilitando a sua participação. Diante deste obstáculo, cada participante portador de limitação visual, no PROINESP, deveria ser acompanhado por um vidente. No caso específico da Prof 2, verifica-se que a mesma possui maior conhecimento de informática do que a pessoa que a acompanha.

Apresenta-se o relato de uma experiência de superação, de vontade e de vitória diante de uma forma de exclusão tecnológica que são as ferramentas que não seguem um padrão de acessibilidade.

\section{SUPERANDO A LIMITAÇÃO DAS FERRAMENTAS DE INTERAÇÃO E DE COMUNICAÇÃO}

As ferramentas de interação e de comunicação devem seguir padrões de acessibilidade para possibilitar o acesso pelos PNEEs com limitação visual. A utilização de leitores de telas como o Virtual Vision e o Jaws possibilitam o acesso ao computador e à internet. O mesmo em relação ao sistema operacional DOSVOX, que é um programa sonoro, com um sintetizador de voz que possui mais de 70 programas como: cartavox(correio eletrônico), papovox(bate-papo), webvox(para navegar na web), intervox(criação de homepages), calcuvox (calculadora), entre outros. A maioria dos sites são acessíveis, principalmente se forem construídos em html. No entanto, deve haver um cuidado especial com a utilização de Flash e Applets Java que tornam os sites inacessíveis, a utilização de frames e tabelas que dificultam a navegação; as figuras que devem incluir o "alternate name", o atributo "alt" em html, com a descrição, para que o PNEEs com limitação visual saibam do que se trata e quando a figura for um link, ser acompanhada da função que ela simboliza. O mesmo cuidado em relação com as ferramentas de interação como o chat que deve ser adaptado. Um exemplo é o papovox que é um programa de bate-papo falado para portadores de limitação visual e pessoas com visão normal.

O bate-papo do ambiente TelEduc é uma ferramenta de comunicação que não segue os padrões de acessibilidade. Cada vez que uma frase ou palavra é enviada, este atualiza-se no todo, como uma nova página. Ao fazer uso de um leitor de telas, cada vez que a página é atualizada, este começa a leitura desde a primeira palavra enviada. A diferença de um bate-papo sonoro, onde a leitura é realizada frase a frase, possibilita que a pessoa com limitação visual participe em igualdade de condições que os videntes. 
Diante desta possibilidade, havia sido planejado, pela equipe de formadores, a utilização de outras ferramentas de interação, externas ao ambiente, como skype (telefone virtual) ou o papovox, programa de bate-papo do sistema DOSVOX.

Durante o primeiro bate-papo, ingressa no ambiente a Prof 2, com limitação visual, utilizando o Jaws, na interação onde estabeleceu-se 0 seguinte diálogo:

(10:35:52) prof 2 Entra na sala...

(10:36:37) Lizandra fala para Todos: Seja bem-vinda prof 1.

(10:38:00) Eliane Moro fala para prof 2: Achei linda a tua foto no perfil!

(10:39:26) prof 2 fala para Todos: vocês estão me ouvindo?

O questionamento da Prof 2: "Vocês estão me ouvindo?" refere-se ao uso do software de voz que ela estava utilizando. Devido a prática na utilização de leitores de telas, tanto pessoal como com seus alunos, o uso desta terminologia acaba sendo diário e apesar dos demais participantes serem videntes, foi facilmente compreendida a sua colocação.

Verificou-se a ocorrência de alguma dificuldade ao acesso do bate-papo com leitores de telas:

(10:50:53) prof2 fala para Todos: oi gente, não dá pra acompanhar todo o papo. Teria que ler toda a tela o tempo todo.

(11:04:01) prof2 fala para Todos: menina, estou num verdadeiro tiroteio. o jaws pra falar tudo e ele fica misturando as mensagens desde o começo do papo!

Apesar da dificuldade, a Prof 2 superou-as participando ativamente do bate-papo. Diante da dificuldade e do desejo de participar, junto aos demais colegas do bate-papo, as duas professoras não desistiram e superaram acessando a ferramenta de comunicação.

Além da superação das suas limitações, a Prof 2 auxiliou a Prof 3, no acesso ao bate-papo:

(11:09:53) prof2 fala para Todos: a [...] está com um pouco de dificuldade mas ela chega lá.

(11:16:31) prof3 fala para Todos: ... ESTOU MUITO ENROLADA. ESTA DE BATE PAPO DE VIDENTE É MUITO COMPLICADO PARA NÓS POBRES CEGOS.

Ao término do bate-papo as professoras ficaram satisfeitas com a superação das barreiras.

(11:11:27) prof3 fala para Todos: OBRIGADO GENTE PELA FORÇA.BEIJOS E TCHAU

(11:18:39) prof2 fala para Todos: oi gente, a gente se fala por mail. vou ficar com saudades. agora temos mesmo que ir. beijos e beijos.

(11:21:23) prof3 Sai da sala...

(11:34:26) prof2 fala para Todos: obrigada gente! acho que só estamos nós no papo. adorei esse primeiro contato.

Antes de sair do bate-papo, a Prof 2 fez algumas considerações sobre acessibilidade e o uso do leitor de telas Jaws: 
(11:38:31) prof2 sorri para Todos: estou vendo como consigo falar com alguém em especial teria que estudar mais a fundo esse chat.

(11:39:05) prof2 sorri para Todos: ele não me abre a caixa de lista. só abre os emoticons.

(11:41:04) prof2 fala para Todos: ... será bom ter esse tutorial pra gente ver o que pode fazer.

(11:41:48) prof2 fala para Todos: o problema é que quando alguém envia uma mensagem a tela muda e fecha as caixas combinadas onde a gente estiver.

(11:42:41) prof2 fala para Todos: só estou conseguindo porque coloquei o jaws na opção falar tudo. mas aí ele fala até demais. fala o que não deve e atrapalha.

O uso das tecnologias possibilita a inserção das pessoas com necessidades especiais no ambiente virtual. Mas, acima de tudo, propicia que a pessoa possa descobrir-se a si mesma. Neste ambiente o aluno é agente do seu processo de aprendizagem, mas também tem compromisso com 0 aprendizado do grupo. Acredita-se que a superação das limitações está em acreditar que pode superá-las a partir do compartilhamento, da colaboração, da cooperação. A Prof 2 estava preocupada em fazer parte do bate-papo porque gostaria de estar presente na troca, na interação com o grupo, o mesmo acontecendo com a Prof 3. No entanto, como a Prof 2 possui mais conhecimento sobre o uso das ferramentas, esta sentiu-se comprometida, também, com o aprendizado da colega. Segundo Vygotsky apud Rego (1995, p.110), "construir conhecimentos implica numa ação partilhada, já que é através dos outros que as relações entre sujeito e objeto são estabelecidas".

\section{CONSIDERAÇÕES FINAIS}

O relato desta experiência fez-nos refletir sobre a superação das limitações. Quem é limitado? Quem é deficiente? As professoras que conseguiram interagir no bate-papo ou as tecnologias de interação e comunicação? Ao longo deste trabalho, as PNEEs não foram tratadas por deficientes, pois como se pode observar, em nenhum momento elas apresentaram diferenças em relação aos demais componentes da turma, pois acredita-se que é preciso propiciar o acesso às tecnologias para que as limitações sejam superadas.

Pode-se constatar esta afirmação através da declaração da Prof 2:

... coordeno o laboratório de informática do Instituto de Cegos da Paraíba. Esse curso é o que se pode chamar realmente de relação pedagógica. Temos o que aprender e o que ensinar! Nossa primeira tentativa num chat de videntes foi uma aventura! Mas além de conseguir conversar com todos e com ninguém em particular, conseguimos até brincar com as nossas experiências e dificuldades. Alguém que estava por perto me dizia que o jaws não possibilita aos cegos entrar nesse tipo de chat, mas teimosa que sou, igual ao discípulo Tomé, só acredito tentando! No meio do turbilhão acabou dando certo! Continuemos nesse compartilhar.

Este é o início da construção coletiva deste grupo. O exercício desta construção permitirá um novo olhar em relação aos alunos: um olhar para cada um e não somente para o todo. Pois cada SER é único, nas suas 
necessidades, na sua individualidade. Ao mesmo tempo, existe o SOMOS, de uma construção colaborativa, cooperativa, onde todos são comprometidos uns com os outros. O aprendizado de "cada um" depende do aprendizado de "cada outro" e a construção é "nossa", em um ambiente democrático, que propicia a inclusão social, digital e educacional. Que as tecnologias, cada vez mais, propiciem o exercício da cidadania e o acesso das pessoas com necessidades especiais em todas as instâncias da sociedade.

\section{REFERÊNCIAS}

BELARMINO, Joana. O que Vê a Cegueira: desatando os nós de uma experiência. $\quad$ Disponível em: http://intervox.nce.ufrj.br/ joana/textos/tecni06.html Acesso em 28 mar. 2005.

CEREJO, Glauco. Algumas Considerações sobre Limitação Visual.

Disponível em: http://intervox.nce.ufrj.br/ cerejo/cslv.html Acesso em 28 mar. 2005.

DIAS, Gisele Pecchio. América [mensagem pessoal]. Mensagem recebida por <estabel@cpovo.net> em 15 de mar. 2005.

FERREYRA, Erasmo Norberto. A Linguagem Oral na Educação de Adultos. Porto Alegre: Artes Médicas, 1998.

REGO, T. C. Vygotsky: uma perspectiva histórico cultural na educação. Petrópolis: Vozes, 1995.

SANTAROSA, L. M. C. Cooperação na Web entre PNEE: construindo conhecimento no Núcleo de Informática na Educação Especial da Ufrgs. In: Congresso Ibero-americano de Informática na Educação Especial- III CIIEE- SEESP/MEC, Fortaleza : ago. 2002, p. 64-79.

VYGOTSKI, L. S. Obras Escogidas: fundamentos de defectologia. v.5.Madrid: Visor, 1997. 